\title{
Effect of intra- and interspecific interactions on the feeding behavior of two subtidal sea stars
}

\author{
Carlos F. Gaymer*, John H. Himmelman*, Ladd E. Johnson \\ Département de Biologie and GIROQ (Groupe Interuniversitaire de Recherches Océanographiques du Québec), \\ Université Laval, Québec G1K 7P4, Canada
}

\begin{abstract}
Competition and its effects are difficult to demonstrate, as they vary depending on the species present and the environmental conditions in each community. We conducted laboratory and field experiments to evaluate the effects of intra- and interspecific interactions on the use of food resources and behavior of the sea stars Leptasterias polaris and Asterias vulgaris, 2 major predators in subtidal communities of the northern Gulf of St. Lawrence. We demonstrate interference (encounter) competition between the two. For both species, the presence of the other (as detected by both contact and chemical signals) decreased feeding activity and provoked behavioral changes (avoidance, decrease in percentage feeding). These effects were reversible and short-lived, and were more pronounced when there was a shortage of food and when sea stars were exposed to simulated attacks by the other species (involving pedicellarial pinching). L. polaris seemed to be the inferior competitor as (1) it switched to less profitable prey size (smaller mussels, Mytilus edulis) when A. vulgaris was present, and (2) it avoided $A$. vulgaris and reduced its feeding activity when food was scarce. The dominance of $A$. vulgaris is possibly attenuated at our study site (near its northern distributional limit) by the reduction of its fitness when water temperatures are low (most of the year) and during the winter when it migrates to deeper water. Competition for food resources seems to occur periodically (mainly summer), in localized areas (patches and beds of mussels) or when sea stars form dense aggregations in which they are likely to interact frequently. Interactions, and thus the chance of competition, are less likely at greater depths. Coexistence seems to be permitted by both the attenuation of the dominance of $A$. vulgaris and by the great variations in how L. polaris and A. vulgaris interact (strongly affected by variations in prey availability, sea star abundance, and in the patterns of prey use by both sea stars).
\end{abstract}

KEY WORDS: Sea stars · Feeding ecology · Prey preference · Feeding experiments $\cdot$ Behavior · Interference $\cdot$ Competition $\cdot$ Avoidance

Resale or republication not permitted without written consent of the publisher

\section{INTRODUCTION}

Competition has long been considered an important factor structuring intertidal and subtidal marine communities (Connell 1961, 1983, Paine 1966, Schoener $1982,1983)$. However, its importance is difficult to demonstrate (Menge 1972, 1979, Connell 1975, Wiens 1977) and probably varies with the species present and environmental conditions in each community (Schoener 1974, 1982, 1983, Connell 1983). Competi-

${ }^{*}$ Corresponding author.

E-mail: john.himmelman@bio.ulaval.ca tion is more likely to occur in communities where the environment is stable and where species are constantly interacting. Inversely, competition is less likely in highly variable environments or where population levels are reduced by predation (Schoener 1983). The effects of competition can be multifaceted. They can be expressed at the individual level, for example by decreased growth or body size, or by changes in behavior, such as shifts in prey use and dispersion to reduce the density of individuals (Menge 1974, Leviten 1978, Underwood 1988, Arrontes \& Underwood 1991, Hopkins \& Gartner 1992, Skilleter \& Underwood 1993, Grudemo \& Bohlin 2000). Competition may also cause 
changes at the population level, such as migration and decreases in survival and reproductive output (Menge 1974, Schoener 1982, 1983, Resetarits 1997). Ultimately, competition may have evolutionary effects, as changes in the morphology and behavior of different species will influence how many species can coexist in a community and thus community structure (Schoener 1982, Underwood 1988).

Although numerous researchers have made field observations or conducted experiments to study competitive interactions in intertidal and subtidal communities (Connell 1983, Schoener 1983, Sih et al. 1985), few have provided convincing evidence of competition (Underwood 1986, 1988, Skilleter \& Underwood 1993, Worm \& Chapman 1996, Resetarits 1997). Experimental evidence is essential to demonstrate the existence of competitive interactions (Connell 1983, Menge 1979, Underwood 1986, 1988). Most studies of the effects of competition focus on the population level and the existing studies on the individual level deal mainly with the effects on growth or size; few have provided evidence of effects of competition on behavior (see review by Schoener 1983). Many studies suggest that competition may have been important in the past, so that present interactions reflect past evolution that permitted the coexistence of competing species (Connell 1980, Schoener 1982, 1983).

The existence of intraspecific competition by potentially competing species provides 1 indication that there may also be interspecific competition, as the needs for specific resources are more similar among conspecifics than among interspecifics (Reynoldson \& Bellamy 1971, Underwood 1988). Interactions between conspecifics may affect the behavior of individuals in a variety of ways, and result in behavioral regulation of density (e.g. aggression, avoidance), dispersion (Branch 1975, Underwood 1988), and the use of a wider variety of prey and habitats (Branch 1975).

In the northern Gulf of St. Lawrence, the sea stars Leptasterias polaris and Asterias vulgaris are major predators in the subtidal zone. A number of studies report considerable overlap in their use of food and habitats, which indicates they may be competing (Jalbert 1986, Dutil 1988, Himmelman 1991, Himmelman \& Dutil 1991). Gaymer et al. (2001b) provide further evidence of potential competitive interactions, especially among juveniles and small adults ( 0 to 5 and 5 to $20 \mathrm{~cm}$, respectively, as defined by Himmelman \& Dutil 1991) in shallow rocky areas; (1) their preferred prey, the blue mussel Mytilus edulis, is restricted in distribution and rapidly eliminated by the 2 sea stars; (2) as mussels become scarce, sea stars begin to partition prey by size; $(3)$ in the absence of mussels, each species selects different alternate prey; (4) the 2 species are segregated at a small spatial scale ( $1 \mathrm{~m}^{2}$ quadrats).
The abundance and distribution of $L$. polaris and $A$. vulgaris in the Mingan Islands do not appear to be limited by the external factors reported to reduce or prevent competition in other systems (Gaymer et al. 2001b). These factors include selective predation and the effects of parasitism and diseases on the dominant species (Rathcke 1976, Menge 1979, Strong 1982, Hixon \& Menge 1991), and environmental variability that might keep populations below the carrying capacity of the environment (Roughgarden \& Feldman 1975, Wiens 1977, Schoener 1982, Dudgeon et al. 1999) or cause massive mortalities (Menge 1979, Ojeda \& Dearborn 1989). Furthermore, L. polaris and A. vulgaris show no apparent partitioning of prey and habitat in space or time (Gaymer et al. 2001b). Gaymer et al. (2001a) suggest that inter- and intraspecific interactions influence mussel size selection and prey switching by $L$. polaris and A. vulgaris, as these interactions could explain observed differences between prey use in the field (where both intra- and interspecifics were present) and the laboratory (where sea stars were studied individually). The differences in feeding abilities of these species affect their size selection of mussels and use of alternative prey, and shifts in prey selection may reduce potential competitive interactions between the 2 sea stars when food is scarce (Gaymer et al. 2001a). The available data suggest that $A$. vulgaris is dominant over L. polaris, since (1) large adult $(>20 \mathrm{~cm})$ L. polaris show an escape response to $A$. vulgaris and are occasionally eaten by A. vulgaris (Dutil 1988, Himmelman 1991) and (2) large adult $L$. polaris are kleptoparasitized by large adult $A$. vulgaris (Morissette \& Himmelman 2000a). Further, in laboratory experiments, the feeding rate on medium-sized and large mussels was higher for A. vulgaris than for L. polaris (Gaymer et al. 2001a). An increased feeding rate may give $A$. vulgaris a competitive advantage when the preferred prey is scarce. Although interspecific interactions between $L$. polaris and A. vulgaris are frequent, intraspecific interactions should be even more frequent at sites where the 2 sea stars form large conspecific aggregations at different depths (Gaymer et al. 2001b).

To understand how intra- and interspecific interactions affect prey use, one must examine the effect of interactions on the feeding performance (e.g. feeding rate) and behavior (e.g. prey selection) of the species involved. Also, it is useful to know if the effects are permanent or reversible and to establish whether the interactions are mediated by contact or by detection of chemical stimuli. Given that Leptasterias polaris and Asterias vulgaris frequently interact (Gaymer et al. 2001b), that $A$. vulgaris appears to be dominant, and that $L$. polaris does not show size selection of mussels in the field when mussel abundance is decreasing 
(Gaymer et al. 2001a), we predicted that L. polaris should be negatively affected by interactions with $A$. vulgaris. This could be reflected by a reduced feeding rate, by a smaller proportion of individuals feeding, and by shifts in the size of mussels eaten.

The present study (1) evaluates the effects of intraand interspecific interactions on the use of food resources and the behavior of Leptasterias polaris and Asterias vulgaris and (2) determines the nature of the stimulus causing these effects.

\section{MATERIALS AND METHODS}

Laboratory experiments. During summer in 1996, 1997 and 1998, we conducted a series of experiments at Havre St. Pierre, in the northern Gulf of St. Lawrence $\left(50^{\circ} 13^{\prime} 6^{\prime \prime} \mathrm{N}, 63^{\circ} 41^{\prime} 12^{\prime \prime} \mathrm{W}\right)$ to compare prey use by individual Leptasterias polaris and Asterias vulgaris with those of individuals in the presence of other sea stars, either conspecifics or interspecifics. In most tests, we quantified the feeding rate of sea stars supplied with mussels (Mytilus edulis) in 401 aquaria over a $4 \mathrm{~d}$ period (exceptions are indicated). Each aquarium was supplied with a continuous inflow of seawater $\left(1.8 \mathrm{l} \mathrm{min}^{-1}\right)$ pumped from $12 \mathrm{~m}$ depth. For each aquarium, feeding rate was calculated by dividing the total number of mussels consumed per day by the number of sea stars present. All trials, except where specified, were made with individuals measuring 12 to $16 \mathrm{~cm}$ in diameter (corresponding to small adults as defined by Himmelman \& Dutil 1991), the most common size in the field for both $L$. polaris and $A$. vulgaris (Gaymer et al. 2001b). To assure that prey were unlimited, we provided each sea star with twice the maximum number of mussels that had been consumed in preliminary feeding trials, thus providing the sea stars with 24 small (0 to $1.5 \mathrm{~cm}$ in shell length), 8 medium $(1.5$ to $30 \mathrm{~cm})$ and 4 large $(3.0$ to $4.5 \mathrm{~cm})$ mussels. As well-fed sea stars often show little interest in feeding (Rochette et al. 1994), the sea stars were starved for $1 \mathrm{wk}$ prior to each experiment to increase the motivation to feed. At $24 \mathrm{~h}$ intervals during the experiments, we recorded the mussels that were consumed and replaced them with others of the same size.

Feeding rate: We studied the effect of intra- and interspecific interactions on feeding rate by measuring the number of medium-sized mussels consumed by sea stars in 6 different treatments: (1) 1 Leptasterias polaris, (2) 6 L. polaris, (3) 1 Asterias vulgaris, (4) 6 A. vulgaris, (5) $3 \mathrm{~L}$. polaris plus 3 A. vulgaris, and (6) $6 \mathrm{~L}$. polaris plus 6 A. vulgaris per aquarium (the last treatment was run in 551 not 401 aquaria). Each treatment was replicated 3 times in 1996 (at water temperatures of 7 to $12^{\circ} \mathrm{C}$ ) and 4 times in 1997 (at 2.5 to $3^{\circ} \mathrm{C}$ ). For the interspecific treatments, we recorded the exact position of each sea star in each aquarium every $4 \mathrm{~h}$ during the first day to aid in identifying the mussels being consumed by each sea star. After that, we recorded the position only twice a day as we found that this was sufficient given the rate of movement of the sea stars.

Size selection of mussels: We evaluated the effects of intra- and interspecific interactions on the size selection of mussels in 1996 and 1998 by quantifying the number of small, medium-sized and large mussels consumed by sea stars of both species in 6 treatments: (1) 1 Leptasterias polaris, (2) 1 Asterias vulgaris, (3) 6 L. polaris, (4) 6 A. vulgaris, (5) $3 \mathrm{~L}$. polaris plus 3 A. vulgaris, and (6) $6 \mathrm{~L}$. polaris plus 6 A. vulgaris per aquarium (the last treatment was in 551 not 401 aquaria). The proportion of the 3 mussel size groups was similar to that observed in the field $(70,20$ and $10 \%$, respectively: Gaymer et al. 2001). In 1998, we eliminated the 3 L. polaris plus 3 A. vulgaris treatment to increase the number of replicates for the other treatments. Also, this treatment was considered unnecessary as it would represent a confounded experimental design (Underwood 1986). We made 3 replicates of each treatment in 1996 (at 6 to $8^{\circ} \mathrm{C}$ ) and 5 in 1998 (at 7 to $9^{\circ} \mathrm{C}$ ).

Nature of potential stimulus causing interference: To elucidate the type of stimuli affecting the feeding rate, we ran experiments in 1997 in aquaria that were divided by a 2-layered wall (a rigid $1 \mathrm{~cm}$ thick plastic grid perforated by $1 \mathrm{~cm}^{2}$ openings and a plastic mesh with $1 \mathrm{~mm}^{2}$ openings) into a one-third and a two-third section. The wall prevented contact between the sea star being studied, i.e. the 'target' sea star, which was placed in the smaller section and the other sea stars or food that were placed in the larger section. For both Leptasterias polaris and Asterias vulgaris, we ran 4 treatments that differed in regard to what was placed in the larger section. In the first treatment, either 5 conspecifics or 5 interspecifics were placed in the larger section to determine if chemical substances liberated by other sea stars (e.g. saponins: Lucas et al. 1979) affected the feeding rate of the target sea star. In the second, we added 5 conspecifics or 5 interspecifics along with 40 medium-sized mussels to examine if chemical substances liberated during feeding (the initial digestion is extraoral) affected the target sea star. In the third, we added only 40 mediumsized mussels to see how food affected the target sea star. Finally, as a control, trials were conducted with nothing placed in the larger section. In all trials, mussels were supplied to the target sea star after a delay of $12 \mathrm{~h}$ (the delay accentuated the effect of odors on the sea star). Each treatment was repeated 6 times (trials on L. polaris at 3 to $4.5^{\circ} \mathrm{C}$ and those on A. vulgaris at 4 to $10.5^{\circ} \mathrm{C}$ ) and a different target sea star was used for each trial. 
Response to simulated attacks: In 1997 (at 4 to $6^{\circ} \mathrm{C}$ ), we measured daily feeding rates of target sea stars (daily supplied with medium-sized mussels) over a $2 \mathrm{~d}$ period before and after simulated attacks by either interspecifics or plastic (PVC) sea star mimics to determine if the attacks affected feeding rate. The attacks were carried out twice daily (at 10:00 and 17:00 h) over $2 \mathrm{~d}$, and during the attacks food was removed from the aquaria. We tested 24 individuals of each species, of which half were subjected to attacks by starved interspecifics and half to attacks by the mimics (controls). For each attack, we used a plastic forceps first to hold the interspecific, or the mimic, on top of the target sea star (aboral size) for $30 \mathrm{~min}$ (this was done in a small plastic basin), and then to hold the target on top of the interspecific, or the mimic, for the following $30 \mathrm{~min}$. We simulated attacks from both sides because sea stars in dense aggregations in the field can have both oral and aboral contacts with interspecifics (the sea star underneath can use its aboral pedicellaria to pinch the sea star above). Whenever we manipulated a target sea star in an attack by an interspecific (e.g. to maintain it in contact with the interspecific), we also manipulated a sea star in the attack by the mimic for the same length of time. During the attacks we noted the behavior of the sea stars (displacement, avoidance, and observations with a magnifying glass of pedicellaria activity and papulae contraction or dilation).

Temporal changes in presence of interspecifics: To evaluate how sea stars respond to temporal changes in the presence or absence of interspecifics, we monitored the feeding rate of individual target sea stars (daily supplied with medium-sized mussels) over $6 \mathrm{~d}$ in 1998 (at 6 to $10.5^{\circ} \mathrm{C}$ ) in 2 situations: (1) with interspecifics absent during the first $2 \mathrm{~d}$, present during the next $2 \mathrm{~d}$, and again absent during the final $2 \mathrm{~d}$, and (2) with interspecifics present during the first $2 \mathrm{~d}$, absent during the next $2 \mathrm{~d}$, and again present during the final $2 \mathrm{~d}$. Each treatment was repeated 6 times for both Leptasterias polaris and Asterias vulgaris. As in the experiments on feeding rate, we monitored the position of the target sea star to aid us in identifying the mussels it consumed.

Shifts in size selection as result of intraspecific interactions: Differences in size selection by individuals alone compared to individuals in groups of sea stars of the same size, and shifts in selection when different sized sea stars were placed together, could provide evidence of intraspecific competition. In 1998, we studied mussel size selection of sea stars measuring 3 to 5 $\mathrm{cm}$ in diameter (juveniles as defined by Himmelman \& Dutil 1991) and small adult (11 to $16 \mathrm{~cm}$ ) Leptasterias polaris (at 6 to $10^{\circ} \mathrm{C}$ ) and Asterias vulgaris $\left(5\right.$ to $5.5^{\circ} \mathrm{C}$ ) by quantifying the number of small, medium-sized and large mussels consumed by each sea star in 5 different size combinations (each replicated 5 times): 1 juvenile, 6 juveniles, 1 small adult, 6 small adults, 6 juveniles plus 6 small adults (the last treatment was run in 551 not 401 aquaria).

Effect of interactions on feeding in the field. We examined the effect of intra- and interspecific interactions in the field by examining responses of sea stars added to artificial patches of mussels that were set up on a bedrock platform at $6 \mathrm{~m}$ depth (sea urchin barrens) at île au Goélands, $~ 5$ km from Havre St. Pierre. We first delimited 15 circular areas (2 m diameter) with cobbles and removed the other macroorganisms (e.g. sea urchins and other sea stars) from the areas. Two days prior to the experiment we added the mussels to create a $3 \mathrm{~cm}$ thick mussel patch in the center of each circular area (the mussels firmly attached to the substrate during the $2 \mathrm{~d}$ ). The diameter of the patches was $50 \mathrm{~cm}\left(0.20 \mathrm{~m}^{2}\right)$, except for Treatment 5 (20 sea stars) where we increased it to $70 \mathrm{~cm}(0.40$ $\mathrm{m}^{2}$ ) to keep prey availability per sea star constant (the number of sea stars was doubled in this treatment). We made 5 types of additions (each replicated 3 times): (1) 2 Leptasterias polaris, (2) $10 \mathrm{~L}$. polaris, (3) 2 A. vulgaris, (4) 10 Asterias vulgaris, and (5) $10 \mathrm{~L}$. polaris plus $10 \mathrm{~A}$. vulgaris. Our observations indicated that the patches were large enough to prevent interaction between sea stars in the treatments with 2 sea stars. We initiated the trials by placing the sea stars (previously starved in enclosures in the field) on the mussel patches. Then, for each species we quantified (1) percentage of individuals feeding, and (2) number of individuals leaving the $2 \mathrm{~m}$ diameter areas, twice daily during the first $3 \mathrm{~d}$, and then once on Days 5, 7, 10 and 16. On each visit, we also removed any other sea stars observed near the experimental areas.

Statistical analysis. Repeated-measures analyses (uni- and multivariate) were used to test for differences in feeding rate for the 8 different intra- and interspecific combinations of sea stars studied each year, and for the tests of the effects of intra- and interspecific odors on feeding rate (4 different treatments). As univariate analyses are more powerful than multivariate approaches, we used them when the assumption of sphericity (Mauchly's criterion) was met (Crowder \& Hand 1990). When the assumptions of normality and homoscedasticity were not met, the data were ln $(y+1)$-transformed. Normality was tested using Shapiro-Wilk's tests (SAS Institute 1988) and homogeneity of variances using Levene tests (Snedecor \& Cochran 1989). In cases where assumptions were not met, ANOVAs were applied to both the raw and to rank-transformed data, as suggested by Conover (1980), and we present the results of the former when 
they were the same for the 2 analyses. Multiple pairwise comparison tests (LSmeans) were used to test for specific differences within a significant source of variation (SAS Institute 1991). We used the sequential Bonferroni method (Holm 1979, Peres-Neto 1999) to control for Type I error.

We applied $\chi^{2}$-tests (using the adjusted residuals to identify specific differences between observed and expected values: Steel \& Torrie 1980, Agresti 1996) to test for differences in mussel size selection (1) by small adult sea stars (6 different intra- and interspecific combinations of sea stars provided with 3 sizes of mussel) and (2) by juveniles and small adults of both sea stars (6 different intraspecific combinations for each sea star species provided with 3 sizes of mussel). One-way ANOVAs were used to test for differences in the proportion of sea stars feeding and leaving the experimental zone as mussel abundance decreased during the field experiment ( 6 treatments). When assumptions of normality (tested with Shapiro-Wilk's tests) and homoscedasticity (tested with Levene tests) were not met, the data were arcsine-transformed. When these assumptions were not met, we again used the approach of Conover (1980). A multiple pairwise comparison test (LSmeans) was used to test for specific differences within a significant source of variation (SAS Institute 1991), and Type I error was controlled using the sequential Bonferroni method. Comparisons of mussel size selected with size available were made with $\chi^{2}$-tests, using the adjusted residuals to identify specific differences between observed and expected values for each size of mussel (Steel \& Torrie 1980, Agresti 1996).

Paired $t$-tests were used to test for differences in feeding rate before and after adding or removing conspecifics or interpecifics in the experiments to evaluate the effect of changes in the presence of the other species over time, and also to compare feeding rates before and after attacks by interspecifics or mimics. Normality was tested using Shapiro-Wilk's tests and homogeneity of variances using Levene tests. Again, Type I error was controlled using the sequential Bonferroni method.

\section{RESULTS}

\section{Feeding rate}

Leptasterias polaris and Asterias vulgaris reduced their feeding rate when they were in contact with the other species in both the 1996 and 1997 experiments (Fig. 1). This was shown in comparisons between $6 \mathrm{~L}$. polaris (L) or 6 A. vulgaris $(\mathrm{A})$ and the $6 \mathrm{~L}+6 \mathrm{~A}$ treatment (a valid comparison according to Underwood
1986) in both years, and also by the 3L + 3A combination in both years. For $A$. vulgaris the interspecific effect was only significant in the $3 \mathrm{~L}+3 \mathrm{~A}$ combination in 1997, but the same trend was also observed for the $6 \mathrm{~L}+6 \mathrm{~A}$ combination. In 1997, both sea stars increased their feeding rate when they were in contact with conspecifics (Fig. 1). The lower feeding rates of A. vulgaris in 1997 compared to 1996 (observed in all treatments) can be explained by the lower water temperatures in 1997 (2.5 to $3.0^{\circ} \mathrm{C}$ ) than 1996 (7 to $\left.12^{\circ} \mathrm{C}\right)$. The effect of temperature on feeding rates was demonstrated when we examined least-squared fitted regression curves for the 2 sea stars based on individual feeding rates at different temperatures recorded during 7 experiments made between 1996 and 1998 (Fig. 2). ANOVAs showed that regression coefficients ( $\beta$ ) were significant for $A$. vulgaris but not for $L$. polaris (Steel \& Torrie 1980, Sokal \& Rohlf 1981). The feeding rate of $A$. vulgaris increased rapidly with increasing temperature whereas the feeding rate of $L$. polaris was not affected by temperature (Fig. 2). As a result, the 2 sea stars fed at similar rates at $2^{\circ} \mathrm{C}$ and the feeding rate of $A$. vulgaris was almost double that of $L$. polaris at about $12^{\circ} \mathrm{C}$.

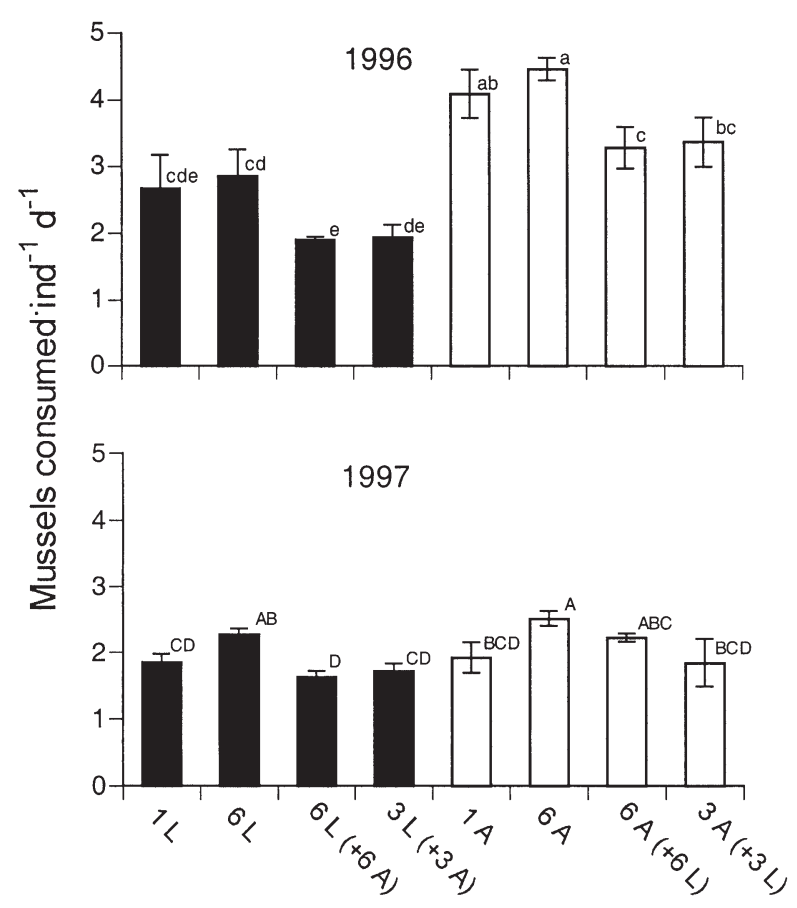

Fig. 1. Leptasterias polaris (L) and Asterias vulgaris (A). Comparison of feeding rates of solitary individuals with rates of individuals in the presence of varying numbers of conspecifics or interspecifics during laboratory experiments in 1996 and 1997. Vertical bars: $\mathrm{SE}_{\text {; }}$ columns sharing the same letter are not significantly different (ANOVA, $p>0.05$ ) 
Fig. 2. Leptasterias polaris and Asterias vulgaris. Relation of feeding rate to water temperature for individual small adults (12 to $16 \mathrm{~cm}$ in diameter) provided with an unlimited supply of meiumsized mussels (Mytilus edulis). The data come from 7 feeding experiments conducted in the laboratory from 1996 to 1998

\section{Size selection of mussels}

In the size-selection experiments in 1996 and 1998, both Leptasterias polaris and Asterias vulgaris preferred medium-sized mussels when they were fed individually and in the presence of conspecifics, except in the case of $A$. vulgaris with conspecifics in 1996, when a switch to smaller mussels was indicated (Fig. 3). When the 2 species were together, L. polaris shifted its selection towards small mussels, whereas A. vulgaris continued to select medium-sized mussels.

Fig. 3. Leptasterias polaris (L) and Asterias vulgaris (A). Comparison of proportion of small, medium-sized and large mussels consumed by individual small adults with the proportion consumed in the presence of conspecifics and in the presence of conspecifics and interspecifics in laboratory experiments in 1996 and 1998. Asterisk above columns indicates significant difference between the proportion selected (black bars) and that available (background histogram) ( $\chi^{2}$-test, $\mathrm{p}<0.05)$. Further details as for Fig. 1

\section{Nature of potential stimulus causing interference}

The experiments conducted in divided aquaria where target sea stars were exposed to odors of food, conspecifics and interspecifics showed that feeding by Leptasterias polaris increased when odors of conspecifics were detected (Fig. 4). This increase was not merely due to the presence of food, and was at the same level irrespective of whether or not the conspecifics were feeding. In contrast, feeding by Asterias vulgaris did not increase when odors of conspecifics were present. The presence of interspecifics alone tended to reduce feeding of both $L$. polaris and A. vulgaris, but the feeding rate was significantly reduced only when the interspecifics were feeding (Fig. 4).

\section{Response to simulated attacks}

Simulated attacks by interspecifics reduced the feeding rate of both Leptasterias polaris and Asterias vulgaris (Fig. 5). However, the feeding rate of $L$. polaris also fell in

\section{6}

Leptasterias polaris
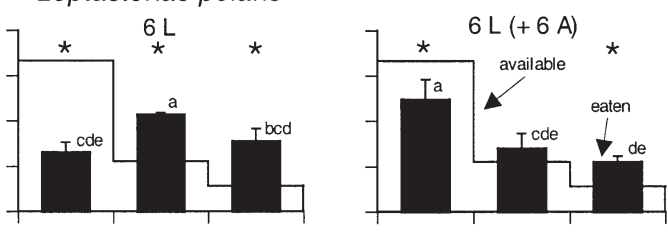

Asterias vulgaris
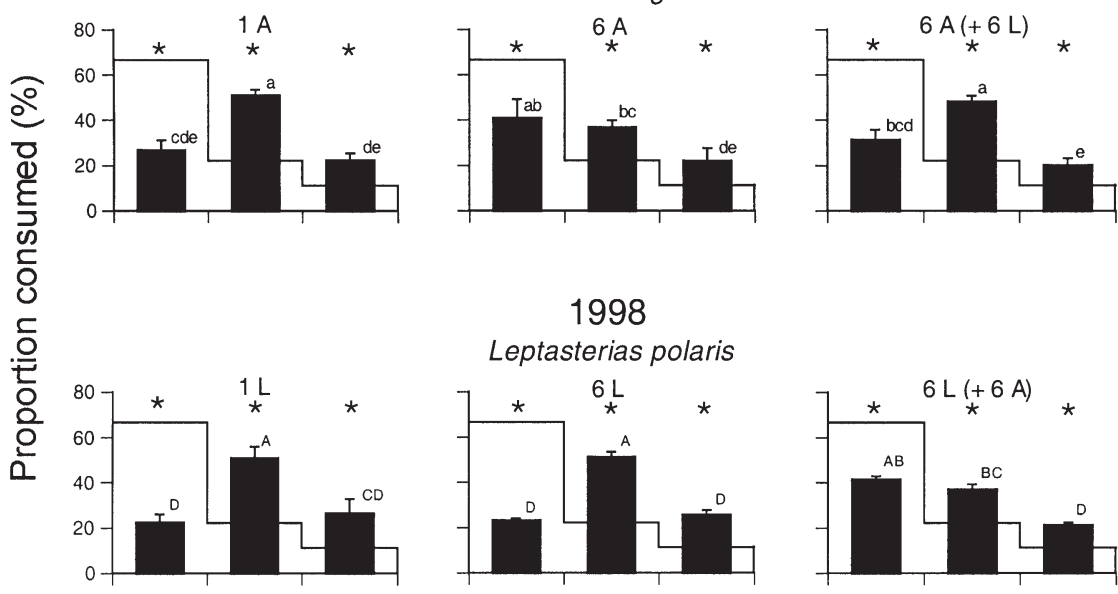

1998

Leptasterias polaris
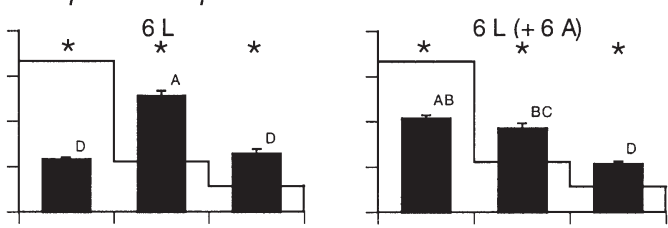

Asterias vulgaris
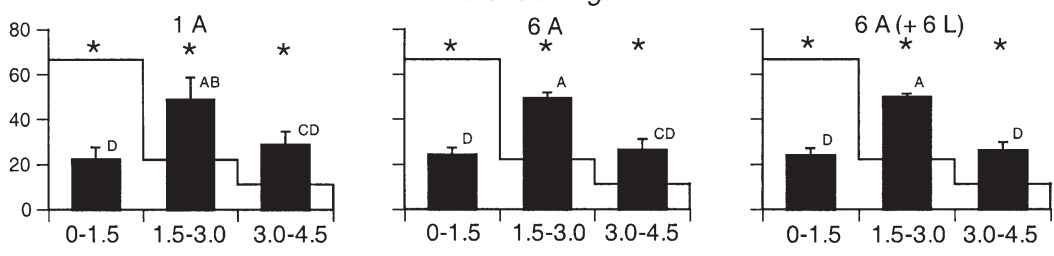

Mussel shell length $(\mathrm{cm})$ 
response to simulated attacks with plastic mimic sea stars, suggesting that physical manipulation rather than the presence of a conspecific caused the decline in feeding rate. The behavioral observations showed that the 2 species had similar responses to interspecifics, highly active pedicellaria (including pinching with ventral pedicellaria when the target sea star was on top of the interspecific), contraction of respiratory papulae in areas of contact, and highly active podia and arms when the target sea star was under an interspecific (Table 1). These behaviors were strongest when the interspecific was on top of the target sea star. Whereas L. polaris moved away slowly when attacked by $A$. vulgaris, $A$. vulgaris rapidly moved away when attacked by L. polaris (in attacks from both above or under). Following many of the simulated attacks by mimics on the 2 sea stars, the target sea star remained in contact with the mimic (showing little agitation) and some moved away slowly. Also, there were few changes in the activity of papulae, pedicellaria, podia or arms in response to mimics.
Table 1. Leptasterias polaris and Asterias vulgaris. Behavioral responses when subjected to simulated attacks by interspecific sea stars and by mimic sea stars. On top: target sea star placed on top of interspecific or mimic; Under: target sea star placed under interspecific or mimic

\begin{tabular}{|c|c|c|}
\hline \multirow{2}{*}{$\begin{array}{l}\text { Species } \\
\text { Position }\end{array}$} & \multicolumn{2}{|l|}{ Attacks by } \\
\hline & Interspecifics & Mimics \\
\hline \multicolumn{3}{|c|}{ Leptasterias polaris } \\
\hline On top & $\begin{array}{l}\text { Slowly moved from } A \text {. vulgaris; } \\
\text { ventral pedicelaria highly active; } \\
\text { pinching of } A \text {. vulgaris with } \\
\text { ventral pedicelaria }\end{array}$ & $\begin{array}{l}30 \% \text { did not move and } \\
70 \% \text { slowly moved off } \\
\text { the mimic sea star }\end{array}$ \\
\hline Under & $\begin{array}{l}\text { Slowly moved from } A \text {. vulgaris; } \\
\text { all pedicelaria highly active; } \\
\text { contraction of respiratory papulae; } \\
\text { podia highly active; } \\
\text { arms highly active }\end{array}$ & $\begin{array}{l}100 \% \text { remained immo- } \\
\text { bile under the mimic } \\
\text { sea star }\end{array}$ \\
\hline \multicolumn{3}{|c|}{ Asterias vulgaris } \\
\hline On top & $\begin{array}{l}\text { Rapid movement from } L . \text { polaris; } \\
\text { ventral pedicelaria highly active } ; \\
\text { pinching of } L . \text { polaris with ventral } \\
\text { pedicelaria; } \\
\text { respiratory papulae dilated }\end{array}$ & $\begin{array}{l}50 \% \text { did not move and } \\
50 \% \text { slowly moved off } \\
\text { the mimic seastar; } \\
\text { respiratory papulae } \\
\text { dilated }\end{array}$ \\
\hline Under & $\begin{array}{l}\text { Rapid movement from L. polaris; } \\
\text { all pedicelaria highly active; } \\
\text { contraction of respirator papulae; } \\
\text { podia highly active; } \\
\text { arms highly active }\end{array}$ & $\begin{array}{l}33 \% \text { did not move and } \\
67 \% \text { slowly moved } \\
\text { away from the mimic } \\
\text { sea star }\end{array}$ \\
\hline
\end{tabular}

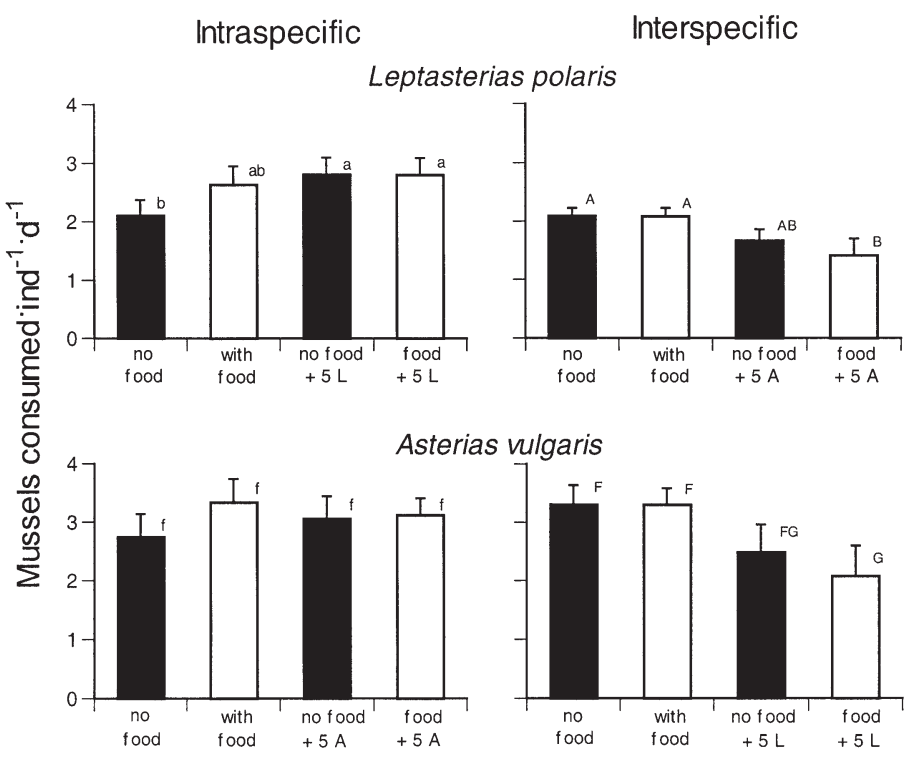

Fig. 4. Leptasterias polaris (2) and Asterias vulgaris. Laboratory experiments examining effects of odors of food, conspecifics and interspecifics on the feeding rate of individual seastars. Further details as for Fig. 1

\section{Temporal changes in presence of interspecifics}

The feeding trials in which interspecifics were sequentially added or removed also showed that the presence of interspecifics reduced feeding of both sea stars (Fig. 6). The effects of interspecifics were short-lived, and disappeared soon after the interspecifics were removed.

\section{Shifts in size selection as result of intraspecific interactions}

In the experiment on intraspecific effects on size selection of mussels, we observed a shift from mediumsized to small mussels (the most available size) when the density of juvenile Leptasterias polaris was increased from 1 to 6 per aquarium (Fig. 7). When 6 juvenile and 6 small adult $L$. polaris were placed together, the small adults more strongly selected medium-sized mussels than in the absence of juveniles. Intraspecific effects were not observed for juvenile Asterias vulgaris, but small adults shifted toward feeding on small mussels both in response to an increase in the density of small adults and in response to the presence of juveniles (Fig. 7). Thus, there was a broadening of the diet of small adult $A$. vulgaris, as observed in the size-selection experiment in 1996 (Fig. 3). 


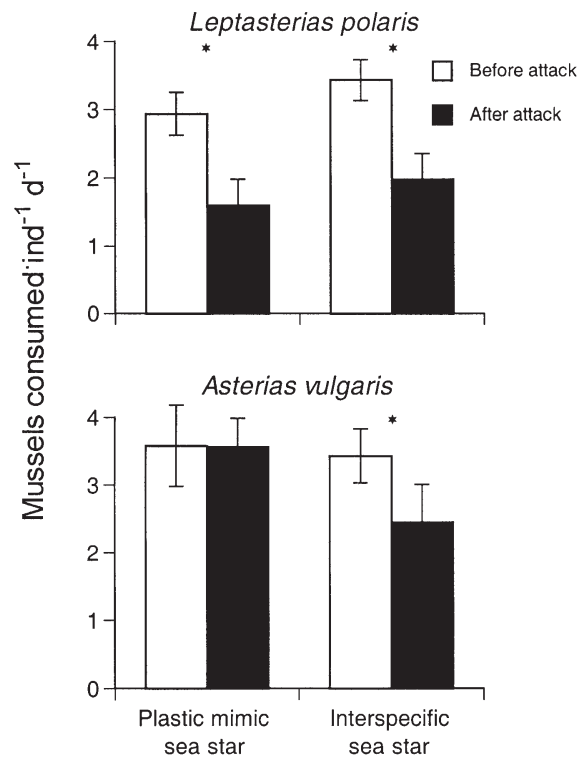

Fig. 5. Leptasterias polaris and Asterias vulgaris. Effect of twice-daily simulated attacks by plastic mimic sea stars and by interspecifics on the feeding rate of individual sea stars. Vertical bars: $\mathrm{SE}_{i}{ }^{*}$ significant difference in feeding rates after the attack (paired $t$-tests, $p<0.05$ )

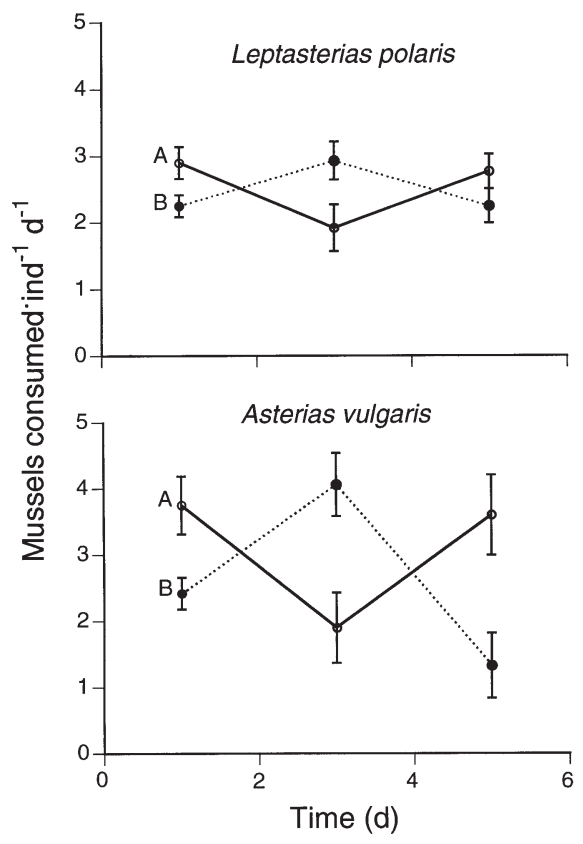

Fig. 6. Leptasterias polaris and Asterias vulgaris. Effect of temporal changes in the presence or absence of interspecifics on the feeding rate of individual sea stars. A: interspecifics absent during the first $2 \mathrm{~d}$, present during the next $2 \mathrm{~d}$, and again absent during the final $2 \mathrm{~d}$; $\mathrm{B}$ : interspecifics present during the first $2 \mathrm{~d}$, absent during the next $2 \mathrm{~d}$, and again present during the final $2 \mathrm{~d}$. In all cases feeding rates are different between consecutive $2 \mathrm{~d}$ periods (paired $t$-tests, $\mathrm{p}<0.05$ ). Vertical bars: \pm SE
Leptasterias polaris

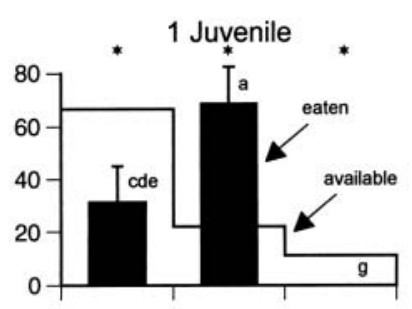

Asterias vulgaris

1 Juvenile
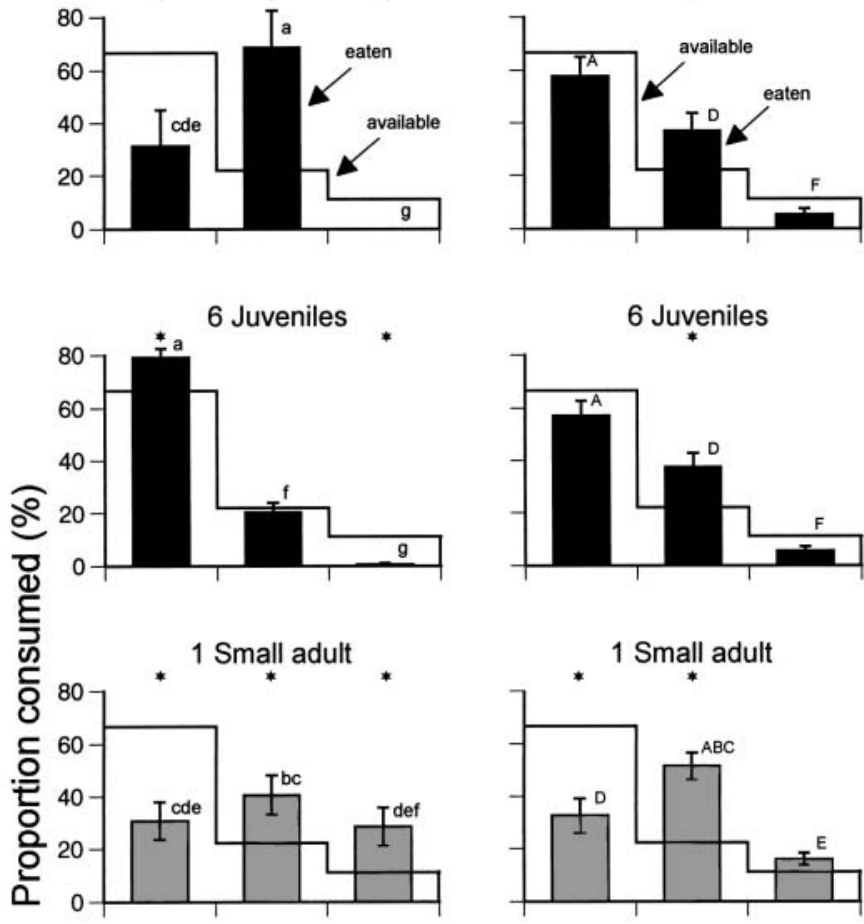

6 Juveniles
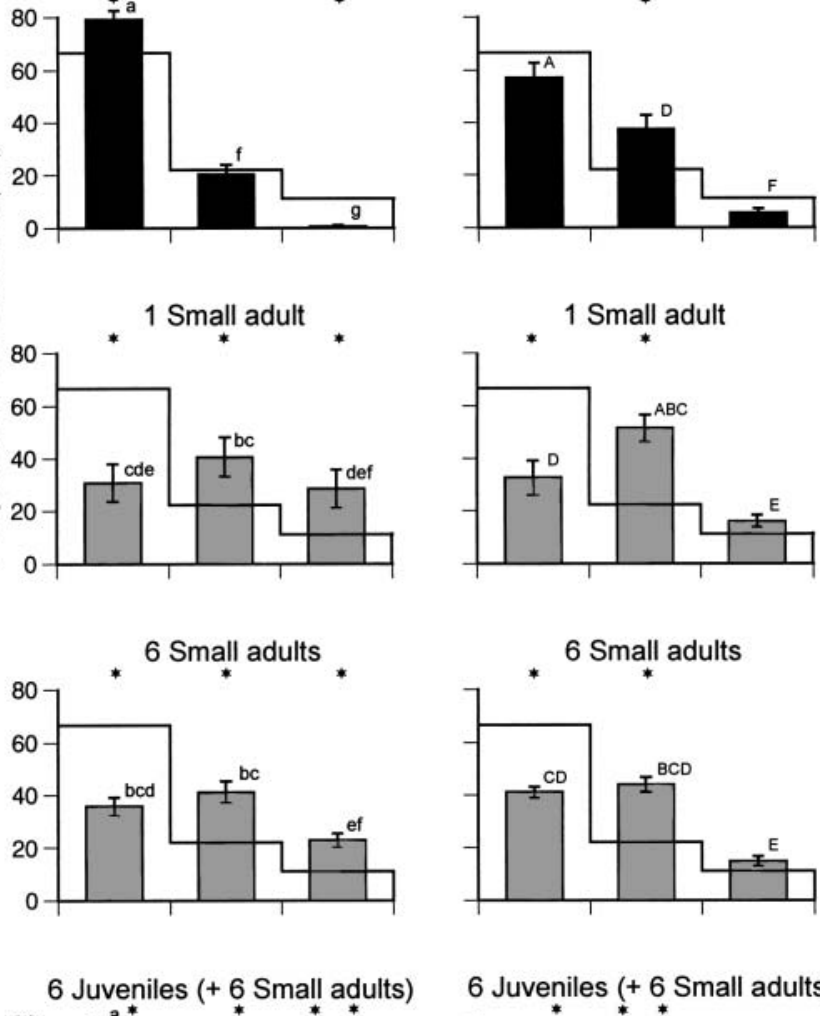

6 Juveniles $(+6$ Small adults)
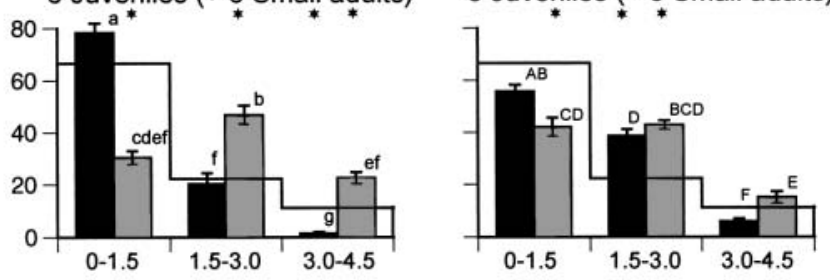

Mussel shell length $(\mathrm{cm})$

Fig. 7. Leptasterias polaris and Asterias vulgaris. Comparison of proportion of small, medium-sized and large mussels consumed by individual juveniles ( 3 to $5 \mathrm{~cm}$ in diameter) or small adults $(11$ to $16 \mathrm{~cm})$ with the proportion consumed in the presence of conspecific juveniles or small adults, and with juveniles and small adults placed together. Vertical bars: $\pm \mathrm{SE}$; columns sharing the same letter are not different (ANOVA, $\mathrm{p}>$ $0.05){ }_{i}^{*}$ significant difference between the proportion selected and that available (background histogram) $\left(\chi^{2}-\right.$ test, $\left.p<0.05\right)$ 


\section{Effect of interactions on feeding in the field}

In the intraspecific treatments in the field experiment (10 Leptasterias polaris or 10 Asterias vulgaris), although percentage feeding began to decrease slightly by Day 8 (when about $40 \%$ of the mussels had been consumed), it nevertheless remained high, suggesting little or no effect of intraspecific interactions. In contrast, in the interspecific treatment $(10 \mathrm{~L}$. polaris plus $10 \mathrm{~A}$. vulgaris) the proportion of $L$. polaris feeding fell, and was less than $50 \%$ at the end of the experiment (Fig. 8). Also, an increasing proportion of $L$. polaris left the experimental area ( 33\% had left by the end of the experiment). Thus, about $20 \%$ of the sea stars remaining in the experimental zone were not feeding. In contrast, no interspecific effect was observed for A. vulgaris, as $\sim 93 \%$ of the individuals were feeding even when $\sim 80 \%$ of the mussels had been consumed, and most individuals remained in the feeding zone until the end of the experiment (Fig. 8).

\section{DISCUSSION}

In the northern Gulf of St. Lawrence, the abundance of Leptasterias polaris and Asterias vulgaris is probably not controlled by predators, parasites, diseases, or storms (Gaymer et al. 2001b). Moreover, these sea stars show no apparent spatial or temporal partitioning of prey and habitat (Gaymer et al. 2001b). Thus, their coexistence does not appear to be due to external or internal mechanisms decreasing competitive interactions. The only mechanism observed that could lead to partitioning of the preferred prey (the mussel Mytilus edulis) by the 2 sea stars was the partitioning by size. Our results clearly show that intra- and interspecific interactions affect both the use of food resources and the behavior of the sea stars.

For both sea stars, intraspecific interactions generally provoke increased feeding. For Leptasterias polaris this is a result of detection of odors of conspecifics, whether feeding or not, whereas for Asterias vulgaris, physical contact with conspecifics is required to stimulate increased feeding. In contrast, interspecific interactions lead to reduced feeding (e.g. feeding rate). For both species, this involves detection of chemical odors from the other species and the effect is increased when the other species is feeding. Possibly chemical substances liberated during the external digestion (e.g. digestive enzymes) inhibit feeding.

Sea stars use chemoreception to detect prey and natural enemies (Sloan 1980). For example, prey odors have been shown to stimulate searching and feeding by Asterias rubens and Crossaster papposus in Europe (Castilla \& Crisp 1970, Castilla 1972, Heeb 1973, Sloan
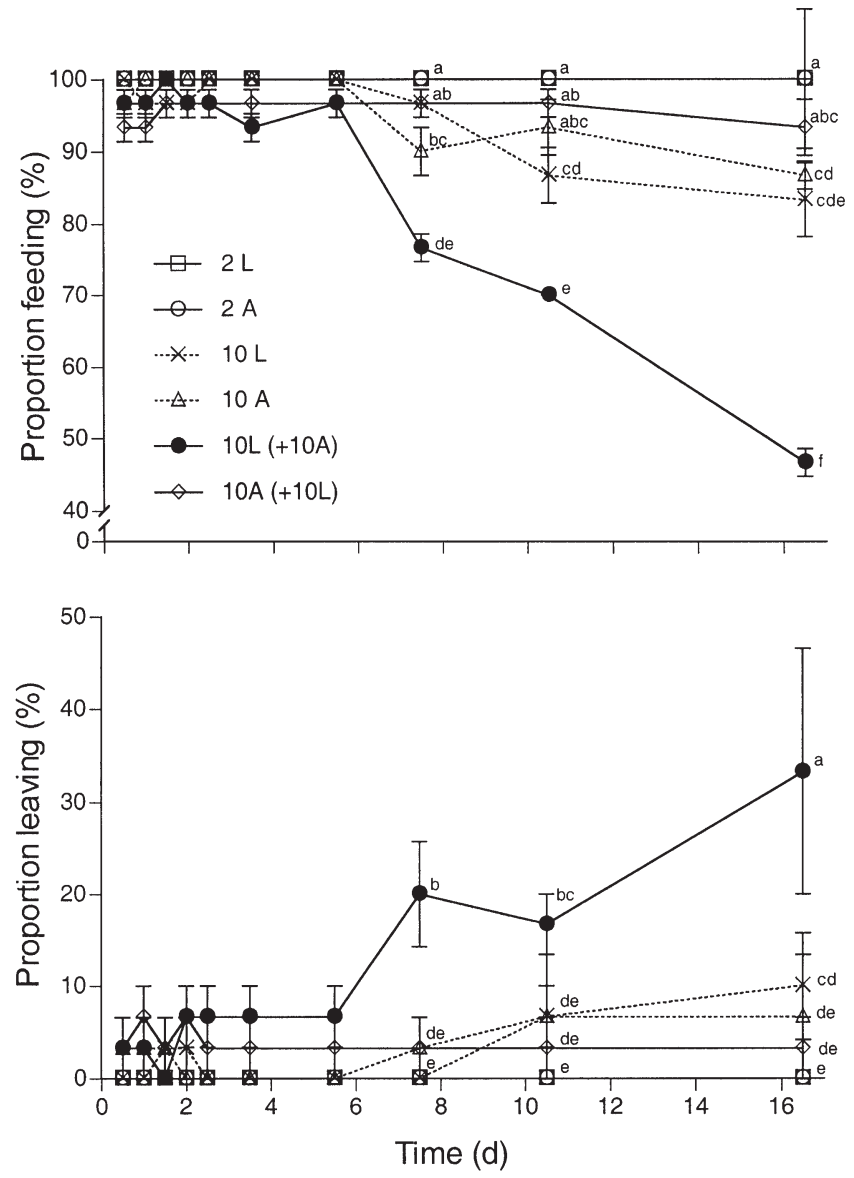

Fig. 8. Leptasterias polaris (L) and Asterias vulgaris (A). Effect of intra- and inter-specific interactions on the proportion feeding (upper graph) and the proportion leaving the experimental area (lower graph) during a $16 \mathrm{~d}$ field experiment conducted in 1998. Treatments were $2 \mathrm{~L}$. polaris, $2 \mathrm{~A}$. vulgaris, $10 \mathrm{~L}$. polaris, $10 \mathrm{~A}$. vulgaris, and $10 \mathrm{~L}$. polaris plus 10 A. vulgaris. Values for $2 \mathrm{~L}$. polaris and 2 A. vulgaris overlap through the experiment at $100 \%$ for proportion feeding and at $0 \%$ for proportion leaving. Symbols sharing the same letter on Days 7,10 and 16 are not significantly different (ANOVA, $\mathrm{p}>0.05$; none of the treatments differed during the first 6 d). Vertical bars: $\pm \mathrm{SE}$

\& Northway 1982). Sea star odors (such as saponins: Lucas et al. 1979, Sloan 1980) are known to provoke avoidance reactions from prey, and from conspecific and interspecific sea stars. Although Sloan (1980) indicates that avoidance of conspecifics may be a way to reduce cannibalism, intraspecific avoidance is more often considered a dispersion mechanism (e.g. to reduce intraspecific competition, Mayo \& Mackie 1976, Sloan 1980, Sloan \& Northway 1982). Avoidance is triggered by aggressive encounters (i.e. interference: Wobber 1975, Palumbi \& Freed 1988) and is mainly observed in species that do not form aggregations (e.g. C. papposus). In contrast, in sea stars that form aggregations, such as $A$. vulgaris and A. rubens, 
juices from digested prey and odors from feeding conspecifics stimulate aggregation and feeding activity (Zafiriou et al. 1972, Sloan \& Campbell 1982, Sloan 1984). Both Leptasterias polaris and A. vulgaris form dense aggregations on patches of prey (Gaymer et al. $2001 b)$ and this behavior concurs with our observations that conspecifics stimulate feeding rather than aggressive or avoidance reactions. In sea stars, contact chemoreception is stronger than distance chemoreception (Sloan \& Northway 1982). For example, studies by Mayo \& Mackie (1976) on several sea star species show that a mechanical and chemical stimulus together elicit a stronger escape response than a chemical stimulus alone. Whereas conspecifics stimulated feeding of both sea stars in our study, the response only resulted from distance chemodetection for $L$. polaris; $A$. vulgaris needed contact with conspecifics.

Interspecific avoidance is often associated with a risk of predation, for example Asterias rubens moves away from odors of its predator, the sea star Crossaster papposus (Castilla \& Crisp 1970, Mayo \& Mackie 1976). However, avoidance may also be used by an inferior competitor to reduce interference from the other species (Menge \& Menge 1974, Sloan 1984). The decreases in feeding rate by Leptasterias polaris and A. vulgaris in our study were probably not associated with a risk of predation, as $L$. polaris has been only observed being eaten by $A$. vulgaris on a few occasions, and the opposite has not been observed (Himmelman 1991, Himmelman \& Dutil 1991). Moreover, neither sea star avoided the other when food was abundant in laboratory trials (C.F.G. pers. obs.); only the feeding rate was affected. Thus, there is an interference interaction whereby interspecifics inhibit feeding (encounter competition sensu Schoener 1983). Sloan (1984) similarly observed that C. papposus may interfere with the feeding of $A$. rubens. When the preferred prey is abundant in the field (e.g. dense patches of mussels), L. polaris and A. vulgaris often form dense aggregations in which they frequently touch one another and show no apparent signs of avoidance (Gaymer et al. 2001b). We only observed 2 instances of avoidance. In the first case, L. polaris avoided A. vulgaris when food was scarce in the latter part of the field experiment; this was possibly a mechanism to avoid competition. The second case was when both sea stars were subjected to simulated attacks by interspecifics (both cases are discussed below). We previously noted interspecific avoidance at a small spatial scale $\left(1 \mathrm{~m}^{2}\right.$ quadrats) at greater depths (where mussels are absent), possibly due to competitive interactions between the 2 sea stars (Gaymer et al. 2001b). We also found that the importance of interspecific interactions depends on the availability of mussels. Thus, when the 2 species co-occurred in areas of high mussel abun- dance, they fed on the same prey species and size, and similar proportions of individuals were feeding, whereas when mussels were scarce they switched to different alternative prey and percentage feeding decreased.

Both Leptasterias polaris and Asterias vulgaris are opportunistic and readily move away to look for alternative food sources when food abundance decreases (Gaymer et al. 2001b). The interspecific interactions, being short-lived, should not reduce the ability of the sea stars to move on to exploit other food resources. A short-term interspecific effect between sea stars was also reported by Menge \& Menge (1974). In response to Pisaster ochraceus, Leptasterias hexactis reduced its feeding rate until it adjusted its activities to avoid this competitor (e.g. it fed in different microhabitats).

Aggressive attacks are thought to be involved in encounter competition (Schoener 1983). Aggressive behavior may cause harm (e.g. lost time, injuries) to one or both species. Simulated attacks by interspecifics had strong effects on the feeding and behavior of Leptasterias polaris and Asterias vulgaris. Both increased activity of pedicellaria, podia and arms, and contracted papula, when held in contact with the other species. Although we observed pinching by the ventral pedicellaria, we did not observe the level of aggression shown by Pisaster ochraceus towards Leptasterias hexactis (Menge \& Menge 1974). In our study, the responses were caused by chemical and/or mechanical stimuli from the interspecifics, as they were not provoked by the plastic mimic sea stars. The strongest response was when target sea stars were placed under the other species and suggests that the target sensed a risk of predation. This could also be due to pinching of the aboral surface of the target by the ventral pedicellaria of the interspecific on the top. The more rapid escape response of $A$. vulgaris may merely reflect the fact that this sea star generally moves more rapidly than L. polaris (Gaymer et al. 2001a). The reduction in feeding after aggressive attacks is further evidence of interference between these sea stars. This has also been observed for $L$. hexactis in response to attacks by P. ochraceus (Menge \& Menge 1974).

Intra- and interspecific interactions affect size selection of mussels, but the effects differ for the 2 sea stars. Mussel size partitioning occurs in the field when mussel abundance decreases, and we previously suggested this could act as a mechanism to permit coexistence of the 2 sea stars (Gaymer et al. 2001b). For a variety of taxa, prey size partitioning has been mentioned as a mechanism permitting coexistence of competitors (Dodson 1970, Roughgarden 1974, Schoener 1982, Branch 1984). Gaymer et al. (2001a) indicate that differences in the feeding abilities of Asterias vulgaris and Leptasterias polaris affect how mussels are partitioned. A. vulgaris feeds 
faster on larger mussels than L. polaris, and this probably provides it with a greater energetic intake. The partitioning of mussels by size in our laboratory trials was similar to the partitioning in the field (Gaymer et al. 2001a,b). A. vulgaris continues to select medium-sized mussels, which probably provide the greatest energetic gain (Gaymer et al. 2001a), whereas L. polaris shifts to smaller mussels, which should lead to a reduced energetic intake. The partitioning of mussels by size is likely to reduce competition for the preferred, but scarce, medium-sized mussels. Moreover, neither species has a competitive advantage when feeding on small mussels as both consume small mussels at a similar rate (Gaymer et al. 2001a).

O'Neill et al. (1983) observed that small Asterias vulgaris $(<10 \mathrm{~cm}$ in diameter) broaden the size range of prey consumed as a response to conspecifics. Our comparisons of intra- and interspecific interactions with 12 to $16 \mathrm{~cm}$ Leptasterias polaris and A. vulgaris did not show a clear effect of intraspecific interactions on prey size selection. However, our experiments examining the effects of conspecifics of different sizes showed that size selection of mussels changed in response to an increase in the density of juveniles for $L$. polaris and in response to an increase in the density of small adults for $A$. vulgaris. These responses provided the only evidence of competition between conspecifics, and suggest that the 2 sea stars use different strategies to reduce the effects of intraspecific interactions. When juveniles and small adults of the same species interacted, no broadening of diet, such as that indicated by O'Neill et al. (1983), was observed; the only response was that small adult (12 to $16 \mathrm{~cm}$ ) L. polaris concentrated their feeding on medium-sized mussels.

The various responses to intra- or interspecifics in our laboratory experiments were not caused by a shortage in food resources, as food was always abundant. Thus, responses were caused by interference or stimulation by the other individuals. However, food availability in the field varies markedly and often rapidly declines due to sea star foraging (Gaymer et al. 2001b). Only our field experiment provided information on intra- and interspecific interactions while food abundance was falling. Conspecifics had little effect on feeding activity (at least on the proportion feeding and avoidance behaviors). In contrast, interspecific interactions caused a strong decrease in the proportion of Leptasterias polaris feeding and an increase in the proportion of individuals moving away (neither was observed for Asterias vulgaris). These observations, together with the decreased feeding rate of $L$. polaris in the presence of $A$. vulgaris in the laboratory, further indicate that $A$. vulgaris is the dominant sea star.

The present study showed that both sea stars interfere with each other in what appears to be a type of encounter competition (an interaction having a negative impact such as lost time, stolen food, or injury: Schoener 1983). Both Leptasterias polaris and Asterias vulgaris showed decreased feeding and changes in behavior when interspecifics were present. The interference effects were greater when there was a shortage of food (field experiment). The stimulus was primarily chemical, as the effects were observed in response to the odor of the other species, and the effects were stronger when simulated attacks were involved (possibly because of pedicellarial pinching). The effects of competition are probably more critical for $L$. polaris, which seems to be the inferior competitor: it switched to smaller mussels, avoided $A$. vulgaris, and reduced its feeding activity when food was limited. The dominance of $A$. vulgaris is also supported by the observations of an escape response of large adult $(>20 \mathrm{~cm})$ L. polaris to A. vulgaris, and of kleptoparasitism and occasional predation of large adult $L$. polaris by large adult $A$. vulgaris (Dutil 1988, Himmelman 1991, Morissette \& Himmelman 2000a, b).

The dominance of Asterias vulgaris may be attenuated by environmental conditions. Although at higher temperatures $\left(>8^{\circ} \mathrm{C}\right)$ the feeding rate of $A$. vulgaris on medium-sized mussels is twice that of Leptasterias polaris, this advantage is lost at low temperatures (the two feed at the same rate at 2 to $3^{\circ} \mathrm{C}$ ). The Mingan Islands are in a cold-water region and the period during which A. vulgaris is more efficient at feeding on larger mussels is restricted to just 3 to 4 wk during the year. The low temperatures in the northern Gulf of St. Lawrence are likely to be more critical for $A$. vulgaris, which is near the northern limit of its distribution (Bousfield 1960); thus, its fitness may be less here than in warmer regions. A. vulgaris migrates to deeper water during the winter, probably to avoid such factors as the low temperatures, strong waves, and ice abrasion (Gaymer et al. 2001b). Thus, during this time it cannot forage on its preferred prey (the mussel Mytilus edulis) in shallow water. The interaction between $A$. vulgaris and $L$. polaris is possibly also affected by variability in the recruitment of $A$. vulgaris, which is determined by such factors as fertilization success and larval transport and survival (discussed in Gaymer et al. $2001 \mathrm{~b}$ ). Recruitment of $L$. polaris is probably more stable because of its benthic mode of reproduction (Himmelman et al. 1982, Boivin et al. 1986). A number of studies of marine invertebrates also suggest that interactions between competing species will depend more on recruitment rates than on the reproductive success of sub-populations (Underwood \& Denley 1984, Roughgarden et al. 1984, Connolly \& Roughgarden 1999). Finally, although A. vulgaris may be dominant, $L$. polaris may have some advantages over $A$. vulgaris. For example, it seemed less stressed by the manipula- 
tions in the laboratory and field experiments, as it usually resumed feeding immediately after being manipulated, whereas A. vulgaris often took several hours. Also, during short interruptions in the water supply, $L$. polaris continued to feed whereas $A$. vulgaris stopped feeding.

Competition is more likely to occur when particular ecological conditions increase the interactions between individuals (Wiens 1977, Hines 1982). Competition between Leptasterias polaris and Asterias vulgaris probably occurs periodically (mainly in summer), in localized areas (patches and beds of mussels) or when particular conditions lead to high numbers of sea stars (aggregations on mussels). Such conditions are likely to lead to frequent interactions between the 2 species (due to contact and distance detection). The effect of the interaction will probably be greatest as mussel patches become decimated and L. polaris begins to avoid A. vulgaris. As the effects of competition seem to be short-lived and reversible, they should disappear once the sea stars switch to alternative food sources. We do not know the impact of competitive interactions on the physiology of the sea stars (e.g. metabolic rates). At greater depth, below the mussel bed, interactions between $L$. polaris and A. vulgaris are reduced, because they are segregated at a small spatial scale and feed on different alternative prey $(L$. polaris mainly on Hiatella arctica and A. vulgaris on Ophiopholis aculeata: Gaymer et al. 2001b). Switching to alternative prey may be a mechanism to permit coexistence (Gaymer et al. 2001b), and the alternative prey chosen seems to reflect their respective abilities to consume the prey (Gaymer et al. 2001b). However, there is no evidence that the use of different alternative prey is an evolutionary response to past competitive interactions (Connell 1980). Holbrook \& Schmitt (1989) showed a similar species interaction, whereby the occurrence and strength of competition can vary within the same local population across a resource gradient. Black and striped surfperchs from temperate marine reefs compete for foraging microhabitats in shallow reefs, where they strongly overlap in their use of the Gelidium robustum microhabitat, whereas they do not compete on deep reefs, where the preferred microhabitat is scarce and they feed in different alternative microhabitats according to their foraging abilities. The intensity of competition for these microhabitats increases with decreasing food density during the food-poor season, leading to food partitioning to decrease interspecific competition. Spatial variations in the intensity of competition between interacting species have also been observed for plants, as Dudgeon et al. (1999) showed that the interaction strength between 2 competing macroalgae may vary on small spatial scales (e.g. within the intertidal zone), accord- ing to variations in resource supply, disturbances, and morphological and ecological characteristics of the organisms involved.

Temporal decreases in the dominance of Asterias vulgaris in addition to the great variations in how Leptasterias polaris and A. vulgaris interact (strongly affected by variations in prey availability, sea star abundance, and in the patterns of prey use by both sea stars), probably reduce competition and permit the coexistence of these 2 ecologically similar sea stars. Coexistence is probably also facilitated by the aggregation behavior of both sea stars (especially $A$. vulgaris) and the patchy distribution of the preferred prey (Atkinson \& Shorrocks 1981).

Acknowledgements. We would like to thank M. C. Giasson, J. Gaudette, T. Gosselin, J. F. Raymond, P. Gagnon, E. Marcano, F. Pernet, M. Guay, P. Gauthier and F. Durocher for their extensive help during the field and laboratory work. We are also grateful to $\mathrm{K}$. Brokordt for discussion and insightful comments throughout the study. The paper was further improved by comments of R. T. Paine, J. J. Dodson and J. Bovet, and an anonymous reviewer. The study was funded by NSERC and FCAR operation grants to J.H.H. and L.E.J. C.F.G. received financial support from the Québec Government, GIROQ, and the Biology Department of Université Laval.

\section{LITERATURE CITED}

Agresti A (1996) An introduction to categorical data analysis. John Wiley \& Sons, New York

Arrontes J, Underwood AJ (1991) Experimental studies on some aspects of the feeding ecology of the intertidal starfish Patiriella exigua. J Exp Mar Biol Ecol 148:255-269

Atkinson WD, Shorrocks B (1981) Competition on a divided and ephemeral resource: a stimulation model. J Anim Ecol 50:461-471

Boivin Y, Larrivée D, Himmelman JH (1986) Reproductive cycle of the subartic brooding asteroid Leptasterias polaris. Mar Biol 92:329-337

Bousfield EL (1960) Canadian Atlantic sea shells. National Museum of Canada, The Queen's Printer, Ottawa

Branch GM (1975) Mechanisms reducing intraspecific competition in Patella spp.: migration, differentiation and territorial behaviour. J Anim Ecol 44:575-600

Branch GM (1984) Competition between marine organisms: ecological and evolutionary implications. Oceanogr Mar Biol Annu Rev 22:429-593

Castilla JC (1972) Responses of Asterias rubens to bivalve prey in a Y-maze. Mar Biol 12:222-228

Castilla JC, Crisp DJ (1970) Responses of Asterias rubens to olfactory stimuli. J Mar Biol Assoc UK 50:829-847

Connell JH (1961) The influence of interspecific competition and other factors on the distribution of the barnacle Chthamalus stellatus. Ecology 42:710-723

Connell JH (1975) Some mechanisms producing structure in natural communities: a model and evidence from field experiments. In: Cody ML, Diamond JM (eds) Ecology and evolution of communities. Belknap Press, Harvard University, Cambridge, MA, p 460-490 
Connell JH (1980) Diversity and the coevolution, or the ghost of competition past. Oikos 35:131-138

Connell JH (1983) On the prevalence and relative importance of interspecific competition: evidence from field experiments. Am Nat 122:661-696

Connolly SR, Roughgarden J (1999) Theory of marine communities: competition, predation, and recruitment-dependent interaction strength. Ecol Monogr 69:277-296

Conover WJ (1980) Practical nonparametric statistics. John Wiley \& Sons Inc, New York

Crowder MJ, Hand DJ (1990) Analysis of repeated measures. Chapman \& Hall, London

Dodson SI (1970) Complementary feeding niches sustained by size-selective predation. Limnol Oceanogr 15:131-137

Dudgeon SR, Steneck RS, Davison IR, Vadas RL (1999) Coexistence of similar species in a space-limited intertidal zone. Ecol Monogr 69:331-352

Dutil C (1988) Partage des ressources alimentaires et comportement de prédation des étoiles de mer de la communauté infralittorale du golfe du Saint-Laurent. MSc thesis, Université Laval, Québec City

Gaymer CF, Himmelman JH, Johnson LE (2001a) Use of prey resources by the seastars Leptasterias polaris and Asterias vulgaris: a comparison between field observations and laboratory experiments. J Exp Mar Biol Ecol 262:13-30

Gaymer CF, Himmelman JH, Johnson LE (2001b) Distribution and feeding ecology of the seastars Leptasterias polaris and Asterias vulgaris in the northern Gulf of St. Lawrence, eastern Canada. J Mar Biol Assoc UK 81:827-843

Grudemo J, Bohlin T (2000) Effects of sediment type and intra- and interspecific competition on growth rate of the marine snails Hydrobia ulvae and Hydrobia ventrosa. J Exp Mar Biol Ecol 253:115-127

Heeb MA (1973) Large molecules and chemical control of feeding behavior in the starfish Asterias forbesi. Helgoländer Wiss Meeresunters 24:425-435

Himmelman JH (1991) Diving observations of subtidal communities in the northern Gulf of St. Lawrence. In: Therriault JC (ed) The Gulf of St. Lawrence: small ocean or big estuary? Can Spec Publ Fish Aquat Sci 113:319-332

Himmelman JH, Dutil C (1991) Distribution, population sizestructure and feeding of subtidal seastars in the northern Gulf of St. Lawrence. Mar Ecol Prog Ser 76:61-72

Himmelman JH, Lavergne Y, Cardinal A, Martel G, Jalbert P (1982) Brooding behaviour of the northern sea star Leptasterias polaris. Mar Biol 68:235-240

Hines AH (1982) Coexistence in a kelp forest: size, population dynamics, and resource partitioning in a guild of spider crabs (Brachyura, Majidae). Ecol Monogr 52:179-198

Hixon MA, Menge BA (1991) Species diversity modifies the interactive effects of predation and competition. Theor Popul Biol 39:178-200

Holbrook SJ, Schmitt RJ (1989) Resource overlap, prey dynamics, and the strength of competition. Ecology 70:1943-1953

Holm S (1979) A simple sequential rejective multiple test procedure. Scand J Stat 6:65-70

Hopkins TL, Gartner JV (1992) Resource-partitioning and predation impact of a low-latitude myctophid community. Mar Biol 114:185-197

Jalbert P (1986) La répartition des populations de Buccinum undatum et des autres prédateurs benthiques dans la communauté infralittorale du nord du golfe du Saint-Laurent. MSc thesis, Université Laval, Québec City

Leviten PJ (1978) Resource partitioning by predatory gastropods of the genus Conus on subtidal Indo-Pacific coral reefs: the significance of prey size. Ecology 59:614-631
Lucas JS, Hart RJ, Howden ME, Salathe R (1979) Saponins in eggs and larvae of Acanthaster planci (L.) (Asteroidea) as chemical defenses against planktivorous fish. J Exp Mar Biol Ecol 40:155-165

Mayo P, Mackie AM (1976) Studies of avoidance reactions in several species of predatory British seastars (Echinodermata: Asteroidea). Mar Biol 38:41-49

Menge BA (1972) Competition for food between two intertidal starfish species and its effect on body size and feeding. Ecology 53:635-644

Menge BA (1974) Effect of wave action and competition on brooding and reproductive effort in the seastar, Leptasterias hexactis. Ecology 55:84-93

Menge BA (1979) Coexistence between the seastars Asterias vulgaris and $A$. forbesi in a heterogeneous environment: a non-equilibrium explanation. Oecologia 41:245-72

Menge JL, Menge BA (1974) Role of resource allocation, aggression and spatial heterogeneity in coexistence of two competing intertidal starfish. Ecol Monogr 44:189-209

Morissette S, Himmelman JH (2000a) Subtotal food thieves: interaction of four invertebrates kleptoparasites with the seastar Leptasterias polaris. Anim Behav 60:531-543

Morissette S, Himmelman JH (2000b) Decision of the asteroid Leptasterias polaris to abandon its prey when confronted with the predatory asteroid Asterias vulgaris. J Exp Mar Biol Ecol 252:151-157

Ojeda FP, Dearborn JH (1989) Community structure of macroinvertebrates inhabiting the rocky subtidal zone in the Gulf of Maine, USA: seasonal and bathymetric distribution. Mar Ecol Prog Ser 57:147-162

O'Neill SM, Sutterlin AM, Aggett D (1983) The effects of sizeselective feeding by starfish (Asterias vulgaris) on the production of mussels (Mytilus edulis) cultured on nets. Aquaculture 35:211-220

Paine RT (1966) Food web complexity and species diversity. Am Nat 100:65-75

Palumbi SR, Freed LA (1988) Agonistic interactions in a keystone predatory starfish. Ecology 69:1624-1627

Peres-Neto PR (1999) How many statistical tests are too many? The problem of conducting multiple ecological inferences revisited. Mar Ecol Prog Ser 176:303-306

Rathcke BJ (1976) Competition and coexistence within a guild of herbivorous insects. Ecology 57:76-87

Resetarits WJ (1997) Interspecific competition and qualitative competitive asymmetry between two benthic stream fish. Oikos 78:429-439

Reynoldson TB, Bellamy LS (1971) The establishment of interspecific competition in field populations, with an example of competition in action between Polycelis nigra (Müll.) and $P$. tenuis (Ijima) (Turbellaria, Tricladida). Proc Adv Stud Inst Dyn Numb Popul 1970:282-297

Rochette R, Hamel JF, Himmelman JH (1994) Foraging strategy of the asteroid Leptasterias polaris: role of prey odors, current and feeding status. Mar Ecol Prog Ser 106:93-100

Roughgarden J (1974) Species packing and the competition function with illustrations from coral reef fish. Theor Popul Biol 5:163-186

Roughgarden J, Feldman M (1975) Species packing and predation pressure. Ecology 56:489-492

Roughgarden J, Gaines S, Iwasa Y (1984) Dynamics and evolution of marine populations with pelagic larval dispersal. In: May RM (ed) Exploitation of marine communities. Report of the Dahlem Workshop, Springer-Verlag Berlin, p 111-128

SAS Institute (1991) SAS/STAT user's guide, Release 6.03 edn. SAS Institute Press, Cary, NC

Schoener TW (1974) Resource partitioning in ecological communities. Science 185:27-39 
Schoener TW (1982) The controversy over interspecific competition. Am Sci 70:586-595

Schoener TW (1983) Field experiments on interspecific competition. Am Nat 122:240-280

Sih A, Crowley P, McPeek M, Petranka J, Strohmeier K (1985) Predation, competition, and prey communities: a review of field experiments. Annu Rev Ecol Syst 16: 269-311

Skilleter GA, Underwood AJ (1993) Intra- and interspecific competition for food in infaunal coral reef gastropods. J Exp Mar Biol Ecol 173:29-55

Sloan NA (1980) Aspects of the feeding biology of asteroids. Oceanogr Mar Biol Annu Rev 18:57-124

Sloan NA (1984) Interference and aggregation: close encounters of the starfish kind. Ophelia 23:23-31

Sloan NA, Campbell AC (1982) Perception of food. In: Jangoux M, Lawrence JM (eds) Echinoderm nutrition. AA Balkema, Rotterdam, p 3-23

Sloan NA, Northway SM (1982) Chemoreception by the asteroid Crossaster papposus (L.). J Exp Mar Biol Ecol 61:85-98

Snedecor GW, Cochran WG (1989) Statistical methods, 8th edn. Iowa State University Press, Ames, IA

Sokal RR, Rohlf FJ (1981) Biometry: the principles and practice of statistics in biological research, 2nd edn. WH Freeman \& Co., New York

Steel R, Torrie J (1980) Principles and procedures of statistics, a biometrial approach. McGraw Hill, New York

Strong DR (1982) Harmonious coexistence of hispine bettles

Editorial responsibility: John Lawrence (Contributing

Editor), Tampa, Florida, USA on Heliconia in experimental and natural communities. Ecology 63:1039-1049

Underwood AJ (1986) The analysis of competition by field experiments. In: Kikkawa J, Anderson DJ (eds) Community ecology: pattern and process. Blackwells, Melbourne, p 240-268

Underwood AJ (1988) Design and analysis of field experiments on competitive interactions affecting behaviour of intertidal animals. In: Chelazzi G, Vannini M (eds) Behavioral adaptation to intertidal life. Plenum Press, New York, p 333-357

Underwood AJ, Denley EJ (1984) Paradigms, explanations, and generalizations in models for the structure of intertidal communities on rocky shores. In: Strong DR, Simberloff D, Abele LG, Thistle AB (eds) Ecological communities: conceptual issues and the evidence. Princeton University Press, NJ, p 151-180

Wiens JA (1977) On competition and variable environments. Am Sci 65:590-597

Wobber DR (1975) Agonism in asteroids. Biol Bull 148: 483-496

Worm B, Chapman ARO (1996) Interference competition among two intertidal seaweeds: Chondrus crispus strongly affects survival of Fucus evanescens recruits. Mar Ecol Prog Ser 145:297-301

Zafiriou O, Whittle KJ, Blumer M (1972) Response of Asterias vulgaris to bivalves and bivalve tissue extracts. Mar Biol 13:137-145

Submitted: April 12, 2001; Accepted: October 12, 2001

Proofs received from author(s): April 2, 2002 